\title{
Hashtags and retweets: using Twitter to aid Community, Communication and Casual (informal) learning
}

\author{
Peter Reed*
}

Centre for Excellence in Evidence-Based Learning and Teaching, Institute of Learning \& Teaching, Faculty of Health \& Life Sciences, University of Liverpool, Liverpool, United Kingdom

(Received 18 September 2012; final version received 13 July 2013)

Since the evolution of Web 2.0, or the Social Web, the way in which users interact with/on the Internet has seen a massive paradigm shift. Web 2.0 tools and technologies have completely changed the dynamics of the Internet, enabling users to create content; be it text, photographs or video; and furthermore share and collaborate across massive geographic boundaries. As part of this revolution, arguably the most significant tools have been those employing social media. This research project set out to investigate student's attitudes, perceptions and activity toward the use of Twitter in supporting learning and teaching. In so doing, this paper touches on a number of current debates in higher education, such as the role (and perceived rise) of informal learning; and debates around Digital Natives/ Immigrants vs. Digital Residents/Visitors. In presenting early research findings, the author considers the $3 \mathrm{Cs}$ of Twitter (T3c): Community, Communication and Casual (informal) learning. Data suggests that students cannot be classed as Digital Natives purely on age and suggests a rethinking of categorisations is necessary. Furthermore, the data suggests students are developing their own personal learning environments (PLEs) based on user choice. Those students who voluntarily engaged with Twitter during this study positively evaluated the tool for use within learning and teaching.

Keywords: Twitter; communication; personal learning environments; Digital Natives/Immigrants; Digital Visitors/Residents

\section{Introduction}

Since the evolution of Web 2.0, or the Social Web, the way in which users interact with/on the Internet has seen a massive paradigm shift. Most notably, the Internet was originally a "tool" with which users can receive information (Web 1), whereas later, users create that information, share and interact with others (Web 2.0).

Web 2.0 tools and technologies have completely changed the dynamics of the Internet, enabling users to create content; be it text, photographs or video; and furthermore share and collaborate across massive geographic boundaries. As part of this revolution, arguably the most significant tools have been those employing social media. As such, social networking sites (SNSs) such as Facebook have seen

\footnotetext{
*Email: peter.jp.reed@gmail.com 
tremendous growth in recent years (Kassens-Noor 2012), culminating in its IPO of roughly $\$ 100 \mathrm{bn}$, where it is suggested more than 80 million shares were sold in the first 30 seconds (Pepitone 2012).

Although it is quickly growing, microblogging site Twitter is not quite at the same scale yet. Although there are a range of blogs and websites discussing and promoting the use of Twitter in education, little published research into how social media is being used to support learning, learners and the student experience exist (Junco, Heiberger, and Loken 2011; Kassens-Noor 2012). However, research demonstrates how students are integrating various tools based on individual choice to form their own personal learning environments (PLEs) (Dabbagh \& Kitsantas 2011; Hall 2009).

This research project set out to investigate student's attitudes, perceptions and engagement in the use of Twitter to support learning and teaching. In so doing, this paper explores relevant literature across three specific and related domains: the role of social networking in the development of the web; the classifications of behaviours of users of the Internet; and the use of such digital tools for learning.

Using Twitter as a voluntary communication platform, and based on early research findings, this paper will also suggests the " $3 \mathrm{Cs}$ of Twitter" $\left(\mathrm{TC}^{3}\right)$ in Education - Community, Communication and Casual (informal) Learning.

\section{The Internet and social media}

Unsurprisingly, statistics show increases in the use of the Internet over time; Roblyer et al. (2010) draw on Pew research (Lenhart et al. 2007) to compare Internet use from 2001 with 2007. In 2001:

- $76 \%$ of online teens said they would miss the Internet if they could no longer go online.

- $48 \%$ said their use of the Internet improves their relationship with friends.

- $32 \%$ say Internet tools help them make new friends.

The Pew figures (Lenhart et al. 2007) go on to suggest that $93 \%$ of teens in 2007 use the Internet, and increasingly "as a venue for social interaction", e.g. create/share content, tell stories and interact (p. 3i). The Pew figures also highlighted that the use of email was decreasing amongst teens, and Junco et al. (2011) suggest learners are beginning to favour communication through social networking tools rather than via email.

Specifically within the UK context, the Office for National Statistics reported the number of people accessing the Internet daily had more than doubled between 2006 and 2012; around $87 \%$ of 16-24 year olds used SNSs in 2012; and mobile Internet traffic more than doubled between 2010 and 2012 (The Office for National Statistics 2013). A YouGov survey $(n=1275)$ highlighted the pervasive nature of social media, and suggested $65 \%$ of the UK online population used Facebook within the last month (February 2012), including 95\% of 16-20 year olds, and 74\% of 21-24 year olds. Interestingly though, the report also suggests that Facebook use is decreasing whilst the use of LinkedIn is increasing (YouGov 2012).

Boyd \& Ellison define social networks as;

web-based services that allow individuals to: (1) construct a public or semi-public profile within a bounded system, (2) articulate a list of other users with whom they share a 
connection, and (3) view and traverse their list of connections and those made by others within the system. (Boyd \& Ellison 2008, p. 211)

This definition aligns with the ethos of social constructivism - the theory of learning suggesting social interaction is critical to the construction of knowledge (Vygotsky 1967) - and the formation and participation within communities of practice.

Furthermore, Roblyer et al. (2010) identify $60 \%$ of students who use SNSs already use the platforms to discuss their education (in general), with over $50 \%$ discussing specific work (Roblyer et al. 2010). Junco, Heiberger, and Loken (2011) also identify positive correlations between SNS use and student engagement.

Therefore, it makes sense that researchers and academics should look to harness these tools and technologies to enhance the sense of community, support communication between learners and tutors, and enable a means for casual (informal) learning.

\section{Social media and the digital divide}

Before educators implement a range of technologies, it is important to gain an understanding of the unique nature of students, including their current use of technologies. Schofield suggests this consideration of learners, alongside the purpose of teaching and learning activities, is integral before identifying and implementing technologies (Schofield 2006).

In exploring the digital behaviours of students, Roblyer et al. (2010) suggest that learners check SNSs and email with equal regularity, but faculty are more likely to check email rather than SNSs. This could add weight to suggestions that students are more engaged with current technological trends than teaching staff - or what might initially appear to be older generations.

Prensky's (2001) observations led to the categorisation based on their digital behaviour, and suggested users were either Digital Natives or Digital Immigrants;

"Digital Natives" - People born later than 1980, who have some innate confidence in using technology and "all of the other toys and tools of the digital age". (p. 4).

"Digital Immigrants" - An older generation of users who have to adapt current practices (and in some cases lifestyles) to harness technologies.

Prensky's work has been widely criticised for such harsh categorisations and exaggerations (Selwyn 2009; White \& Le Cornu 2011), such as the suggestion that "our students' brains have physically changed" (Prensky 2001, p. 1).

White and Le Cornu (2011) recognise the compelling nature of Prensky's work, however suggest his metaphors, as criticised as they are, relate not only to a different time (e.g. 2001), but also to a different Web (1.0). White and Le Cornu go on to offer a new continuum-based typology for online engagement, with more consideration of the now commonplace social networking services available. Careful not to pigeonhole users into age or technical categories, White and Le Cornu use the metaphor of "Digital Residents" and "Digital Visitors" (White \& Le Cornu 2011).

Digital Visitors are those users who may use a tool to carry out a desired function. The tool may not be the perfect fit for the job, but are happy to make some progress to the aims. When the job is over, the tool is put away again. Visitors are not interested in building profiles online.

Digital Residents on the other hand, see the social web tools as a place, not too dissimilar from a physical building, or a park: places to meet up with friends and interact. The boundaries between the physical and digital worlds are increasingly blurred. 
White and Le Cornu go on to identify Digital Visitors through the metaphor of a garden shed, suggesting:

... Visitors understand the Web as akin to an untidy garden tool shed. They have defined a goal or task and go into the shed to select an appropriate tool which they use to attain their goal. Task over, the tool is returned to the shed. It may not have been perfect for the task, but they are happy to make do so long as some progress is made. (White \& Le Cornu 2011)

In relation to this study, Prensky would suggest that students should all be familiar with SNSs such as Facebook and Twitter, whereas White and Le Cornu would suggest users may or may not engage with social media to different levels depending on their personal aims and views on the tools in question. Of particular interest here is if any data obtained in this study can support either typology.

\section{Social media and PLEs}

Hall (2009) discusses the need to balance formal learning, e.g. structured/timetabled learning opportunities within an institution, with informal learning, e.g. learning outwith the formal structures and technologies provided by the institution. How learners use and traverse these spaces (and indeed concepts) is of interest in this study, and in particular, the social web technologies that support and enable them to do so. The collection of such technologies alongside and in combination with the formal systems of the university, might be considered a "personal learning environment" or "PLE" (Hall 2009). Furthermore, social media tools such as Twitter and Facebook can significantly impact upon their development (Hall 2009; Dabbagh \& Kitsantas 2011; Kassens-Noor 2012). Through adopting such tools, authors suggest learners can address the "blurring of the boundaries" between personal, social spaces and formal learning contexts (Hall 2009). Hall builds on notions that PLEs can "help integrate formal and informal learning" in HE (Dabbagh \& Kitsantas 2011) suggesting they should be integrated in order to enhance learning. However, in this study, there is an emphasis upon learner choice in the development of such environments, which might prove challenging or contradictory in instances where institutions enforce or even restrict participation to particular systems.

In discussing formal learning environments, both sets of authors (Hall and Dabbagh and Kitsantas) use terms such as "Institutionally sponsored", "highly structured", "prescribed learning framework" and "specified learning tasks". These will likely include, for example, the structures in place through institutionally owned virtual learning environments (VLEs). This can be compared with the "learner owned" and "learner developed" PLEs constructed of tools through personal choice and often including Web 2.0 tools. Although traditionally, academics see the two environments separately (Roblyer et al. 2010), Hall identifies evidence suggesting that eLearning as a whole is "rarely seen as separate or special by learners" (p. 32), and that students already use a mix of tools (both personal and Institutional) depending on choice, access and control. He goes on to suggest the ways students blend and deploy both informal and formal tools "underpins their assemblage of a meaningful PLE” (Hall 2009).

This study is largely interested in the use of social media in the development and formation of learner PLEs, as well as learner's attitudes towards their use in learning and teaching. 


\section{The use of Twitter in education}

Twitter was launched in 2006 as a microblogging service (Boyd \& Ellison 2008), enabling users to send tweets of 140 characters. Similar to other SNSs, Twitter enables users to follow the tweets of other users. As the service has developed, additional functionality has enabled users to include a photograph in their tweet, form lists of users, and third-party tools enable longer tweets and simultaneous posts across multiple SNSs.

Literature suggests that those who have experimented using Twitter in teaching and learning agree that it can have a positive impact on student engagement (Kassens-Noor 2012).

Kassens-Noor's (2012) study investigates how students apply, create and retain knowledge when using Twitter, with the leading question: "Does the use of Twitter aid students in learning a particular subject matter? And, if so, in which learning contexts does Twitter offer advantages over more traditional teaching methods?" (p. 12). The implementation of Twitter here was structured, requiring students to tweet about a particular topic in order to complete a credit-bearing assessment. Participants were asked to: tweet daily; raise a cause for concern related to the subject matter as well as suggesting a remedy; and respond to other tweets in relation to the original concern or the remedy.

Although the sample size was low (15 participants), Kassens-Noor (2012) reported positively in relation to the use of Twitter as a "powerful collaboration tool between students", "better suited for creating and sharing large amounts of information" and useful for "informal, out-of-classroom assignments" (p. 16).

In comparison with a second group of students keeping journals, tweeters raised more topics for concern and discussion, but tweets were less reflective - perhaps due to less space, e.g. 140 characters.

Several other authors (Junco, Heiberger, and Loken 2011; Roblyer et al. 2010) have identified Chickering and Gamson's Seven Principles for Good Practice in Undergraduate Education (Chickering \& Gamson 1999) as a foundation for the use of social media in learning and teaching, and as a means to benchmark "engagement". The seven principles of good practice in undergraduate education include:

(1) Encourages student-faculty contact

(2) Encourages cooperation among students

(3) Encourages active learning

(4) Gives prompt feedback

(5) Emphasizes time on task

(6) Communicates high expectations

(7) Respects diverse talents and ways of learning

To this end, the work of Junco, Heiberger, and Loken (2011) is one of the few empirical studies investigating the impact of Twitter on student engagement, with two leading questions:

What effect does encouraging the use of Twitter for educationally relevant purposes have on student engagement?

What effect does encouraging the use of Twitter for educationally relevant purposes have on grades? (p. 121) 
In implementing the tool, researchers ran training sessions on the use of Twitter (including explanations on how hashtags work, tweeting another user, etc.), and embedded its use through mini assignments that needed to be completed. They then captured data on the amount of tweets sent and by how many students. The authors suggest; "Twitter helped students feel more comfortable asking questions they may not be comfortable with asking in class" (Junco, Heiberger, and Loken 2011, p. 127), and furthermore highlighted a positive effect on both student engagement and grades. They then go on to relate their positive experiences with Chickering and Gamson's principles for good practice, suggesting that their research demonstrated:

- Improved contact with faculty (Principle 1)

- Improved communication between students (Principle 2)

- Promoted active learning (Principle 3)

- Prompt feedback (Principle 4)

- Maximise time on task (Principle 5)

- Communicate high expectations (Principle 6)

- Respect for diversity (Principle 7)

Finally, in preparation for a keynote presentation, Steve Wheeler asked students at the University of Plymouth for quotes regarding their thoughts on the use of Twitter. He received a number of replies from students, such as:

- "Twitter, we're better connected"

- "Twitter opens the classroom to the world, but also with this, the world of criticism and debate"

- "Twitter has opened a wealth of opportunities and information I never even knew existed. To be honest, might have to blog now"

\section{Literature review summary}

The literature identified thus far suggests that today's students are increasingly relying on the Internet as a means for "Communication", and largely related to building and maintaining relationships - "Community". It recognises existing attempts to classify users of the Internet, and reports overwhelmingly positive feedback in relation to the use of Twitter in teaching and learning - informal or "Casual" learning.

Limited, but positive feedback from the literature calls for further investigation into the use of Twitter in education, and in particular to explore aspects related to development and participation within a community, as well as communication with, and amongst, groups of students for personal and learning purposes.

This study adds to the small, but growing body of research in relation to the use of Twitter in education. It hopes to add further clarification to the debate around classifying users of the Internet and investigate students' attitudes and practices in relation to Internet access, and in particular, the use of SNSs within the formation of learner-generated, and learner-owned PLEs.

\section{Methodology}

Two lecturers (within the School of Computing and Maths, and School of Healthcare Science) at Manchester Metropolitan University encouraged students to sign up and 
use Twitter as a potential solution to help encourage communication between students; provide a backchannel throughout teaching activities; and aid the communication channels between students and teaching staff.

Students were informed early on that they did not have to sign up to the service, but support was provided for those students wanting to. These students were encouraged to include dedicated hashtags if they wanted to tweet anything related to the course of study.

Twitter was used by the lecturers in five different modules, across two academic periods/years, with hashtags corresponding to the module codes (actual hashtags have been renamed here to preserve anonymity):

\begin{tabular}{lcll}
\hline Hashtag & Year of Study & Level of Study & \multicolumn{1}{c}{ Module Title } \\
\hline$\# 0001$ & $11 / 12$ & 5 (2nd Year) & Multimedia Development \\
$\# 0002$ & $11 / 12$ & 5 (2nd Year) & Multimedia Design \\
$\# 0003$ & $11 / 12$ & 5 (2nd Year) & Human Physiology \\
$\# 0004$ & $12 / 13$ & 5 (2nd Year) & Multimedia Development \\
$\# 0005$ & $12 / 13$ & 6 (2nd Year) & eLearning Multimedia \\
\hline
\end{tabular}

Throughout the duration of the modules, the lecturers would regularly tweet links that might be useful to students as well as being available to answer questions, etc. Through the use of hashtags, these tweets could be captured using the Twitter Developer API, which were then embedded within the corresponding area for the unit in the university's VLE.

Due to collaborative delivery arrangements at the university, a number of teaching staff share the workload of each module, with the consequence that Twitter may have been introduced to different modules at different times of the year. For example, Twitter was introduced to \#0001 students in Week 1 (September 2011), but was not introduced to \#0002 students until Term 2 (January 2012). Similarly, although Twitter was introduced to \#0003 and \#0004 within the first few weeks of the 12/13 academic period, it was not used much until Term 2 (January 2013).

A short questionnaire built using the university's subscription to an online survey tool was sent to students via a link in a VLE announcement/email. Students were aware that completion of the questionnaire was voluntary and that their participation was anonymous.

\section{Questionnaire}

The questionnaire contained 17 questions across two sections, aiming to: (1) gain a picture of the demographics and digital profile of the student group; and (2) identify existing Internet practices and gauge the attitudes toward the use of social media in learning and teaching. The questionnaire contained yes/no, multiple choice and multiple answer questions, with scope for free text comments in response to respondent's perceived benefit of Twitter (Q14). A copy of the complete questionnaire can be found in Appendix 1.

After completion from the 0002 and 0003 groups, two further questions were added to the survey. Firstly, the option of "Gaming" was added to question 7 (relating to online activity), and secondly, an add-on question to Q9 about the use of Facebook was added, asking if respondents have discussed university work on Facebook. 
Table 1. Respondents gender by module.

\begin{tabular}{lccr}
\hline Module & Male & Female & \multicolumn{1}{c}{ Total } \\
\hline MM5362 & $6(14 \%)$ & $4(9.5 \%)$ & $10(23.8 \%)$ \\
MM5361 & $8(19 \%)$ & $2(4.7 \%)$ & $10(23.8 \%)$ \\
6ABL2303 & $4(9.5 \%)$ & $3(7.1 \%)$ & $7(16.6 \%)$ \\
6G5Z2001 & $9(21.4 \%)$ & $3(7.1 \%)$ & $12(28.5 \%)$ \\
63MM6301 & $5(11.9 \%)$ & $0(0 \%)$ & $5(11.8 \%)$ \\
Total & $32(76.1 \%)$ & $10(23.8 \%)$ & $42(100 \%)$ \\
\hline
\end{tabular}

Table 2. Main device for Internet access by gender.

\begin{tabular}{lccc}
\hline & Male & Female & Total \\
\hline Computer & $13(30.6 \%)$ & $1(2.3 \%)$ & $14(33 \%)$ \\
Laptop & $13(30.6 \%)$ & $8(19 \%)$ & $21(49.6 \%)$ \\
Smartphone & $5(11.8 \%)$ & $1(2.3 \%)$ & $6(14 \%)$ \\
Tablet & $1(2.3 \%)$ & $0(0 \%)$ & $1(2.3 \%)$ \\
Total & 32 & 10 & 42 \\
\hline
\end{tabular}

Introductory questions identified age group and gender, with the potential to crosscheck results to determine patterns. Wherever relevant, this data is provided in the following section.

The questionnaire was sent to all 208 students studying the modules detailed above. The 42 responses represent a $20 \%$ response rate.

Ethical approval for this research was granted through the Faculty of Science and Engineering ethics review board. Furthermore, completion of the survey was entirely voluntary and anonymous, adhering to the British Educational Research Association guidelines of "voluntary informed consent" (BERA 2011).

\section{Results}

\section{Student profile}

The first section of the questionnaire aimed to gain a profile of the student population (Table 1). Thirty-seven (88\%) of the respondents were aged between 18 and 21 , whilst only five $(12 \%)$ were aged between 25 and 34 .

Of the respondents, 10 were female, and 32 were male.

Laptops are the preferred device amongst respondents $(50 \%)$, with $80 \%$ use by female respondents $(\mathrm{n}=8)$ (Table 2$)$.

Despite the market surge in demand for tablet devices, only one respondent $(2.3 \%)$ uses a tablet as their primary device for Internet access. The developments in smartphone technologies are beginning to enable users $(n=6,14 \%)$ to use them as primary Internet devices.

\section{Online access}

The next section in the questionnaire aimed to identify how students access the Internet, and how they spend their time online.

Chart 1 demonstrates how $48 \%$ of respondents spend between 11 and 30 hours online per week $(n=20)$, equating to between 1.5 and 4.2 hours per day. However, some students spend considerably less - two respondents spend less than 10 hours 


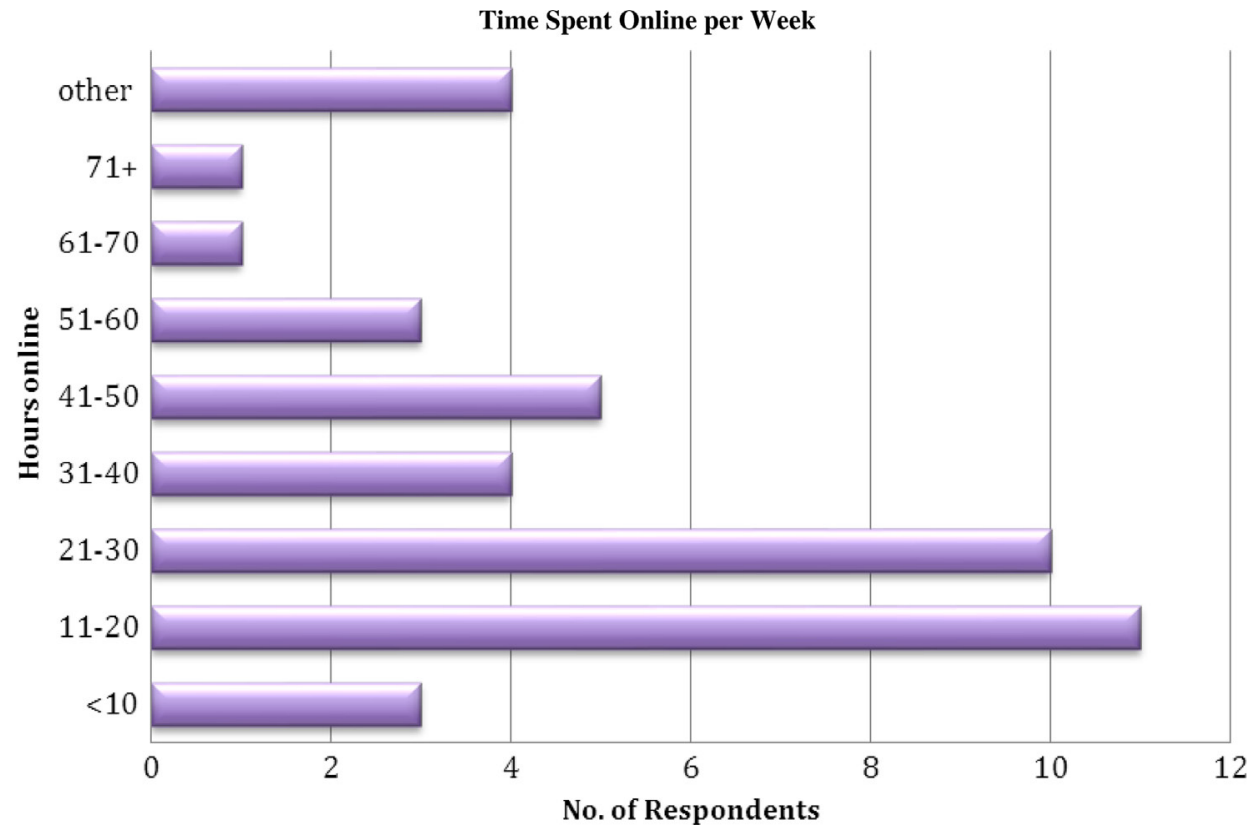

Chart 1. Time spent online.

online per week - and some spend considerably more - five respondents spend more than 51 hours per week online. There were also four "other" responses to this question, including: "Many/Too many" and "Continuously".

The mean time spent online was 33 hours per week.

Chart 2 demonstrates how respondents in the 25-34 age category are less likely to spend significant time online - all of whom spend less than 40 hours online per week. In contrast, 13 respondents (31\%) spend greater than 41 hours online per week, all of which are in the 18-25 age category.

Time Spent Online by Age Group

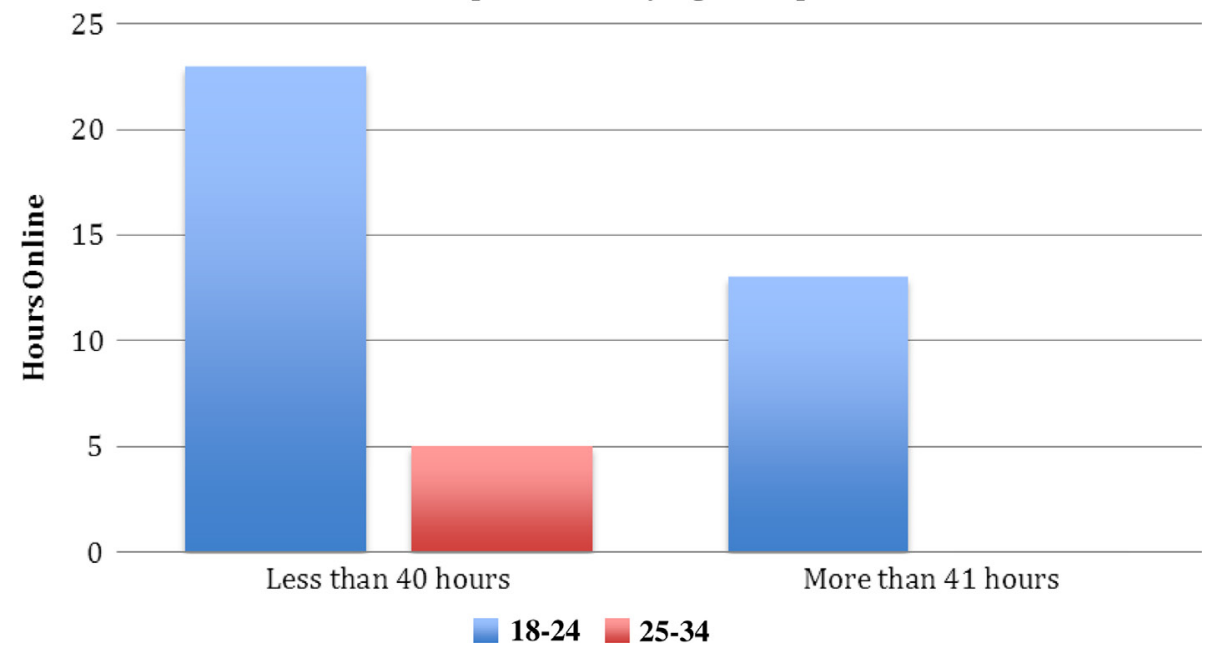

Chart 2. Time spent online by age group. 
Chart 3 demonstrates that respondents perform a range of activities online, with very few activities taking up a large percentage of overall Internet usage. In particular, no respondents spend any more than $70 \%$ of their overall time online in activities related to shopping, news and weather, or banking. In fact, these activities were those that respondents spend least time on.

Although still uneven, respondents demonstrated a more balanced distribution for activities related to social networking and study, with the majority of responses spending between $11 \%$ and $70 \%$ of their overall time online in these activities.

$79 \%$ of respondents engaged in social networking $(n=33)$ between $11 \%$ and $70 \%$ of their overall time online, just as they did in activities related to study (79\%, $\mathrm{n}=33$ ).

Table 3 demonstrates that $31 \%(n=13)$ of $18-24$ year old respondents spend more than $50 \%$ of their overall time online in social networking activities, compared to just $2 \%(n=1)$ of the $25-34$ year olds.

Chart 4 demonstrates the range of practices related to study amongst respondents:

- $14 \%$ of respondents spend less than $10 \%$ of overall Internet time in activities related to study.

- The most common response $(\mathrm{n}=14)$ was between 31 and $50 \%$.

- Only three respondents spend more than $71 \%$ of their overall time in activities related to study.

- $36 \%(\mathrm{n}=8)$ of respondents spend over $50 \%$ of their overall time online engaging in activities related to study.

\section{Time spent online by activity}

35

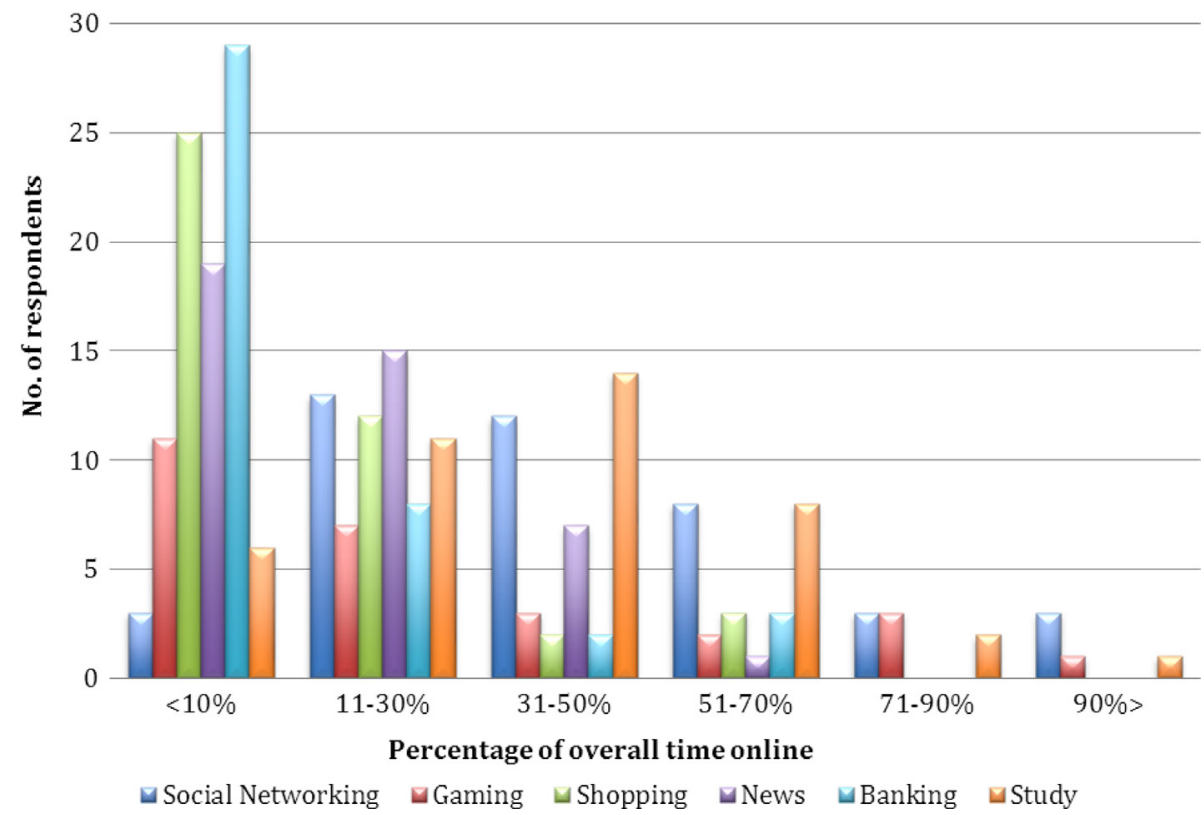

Chart 3. Time spent online by activity. 
Table 3. Time spent in social networking by age group.

\begin{tabular}{lcc}
\hline$\%$ & $18-24$ & $25-34$ \\
\hline$<10$ & 2 & 1 \\
$11-30$ & 11 & 2 \\
$31-50$ & 11 & 1 \\
$51-70$ & 7 & 1 \\
7190 & 3 & 0 \\
$90>$ & 3 & 0 \\
\hline
\end{tabular}

Chart 5 demonstrates smartphone uptake amongst respondents. Android smartphones are the most popular amongst respondents $(33 \%, \mathrm{n}=14)$, closely followed by iPhones $(31 \%, \mathrm{n}=13)$. Eight respondents $(13 \%)$ use Blackberry smartphones and one uses a Nokia phone $(3 \%)$.

A total of $14 \%(n=6)$ of respondents do not own a smartphone.

Chart 6 demonstrates the range in which different people use their smartphones for access to the Internet, with a mix of answers across the boundaries.

A total of 24 respondents $(57 \%)$ with smartphones use them for less than $50 \%$ of their overall Internet activity, whilst $18(43 \%)$ use them for more than this.

Table 4 demonstrates that no respondents aged between 25 and 34 rely on their smartphones for more than $50 \%$ of their overall online activity, whilst a greater range exists amongst the lower age bracket.

Chart 7 compares smartphone users with their social networking activity. This data suggests that iPhone and Android users are more active on SNSs than users of other smartphones, and considerably more active than non-smartphone users.

\section{Use of social networking sites}

This section of the questionnaire focuses on attitudes and practices related to the use of SNSs, and in particular their use within an educational context. Respondents were asked about their prior use of SNS, their views on communication between tutors/ students, and their use of Twitter as a result of this study.

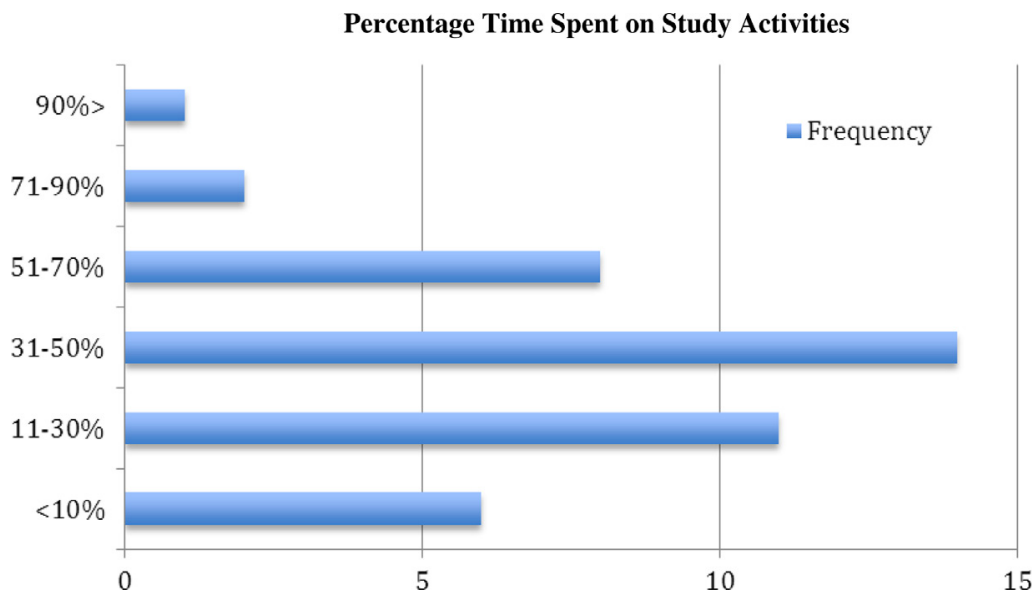

Chart 4. Time spent on study activities. 


\section{Percentage respondents with smartphones}

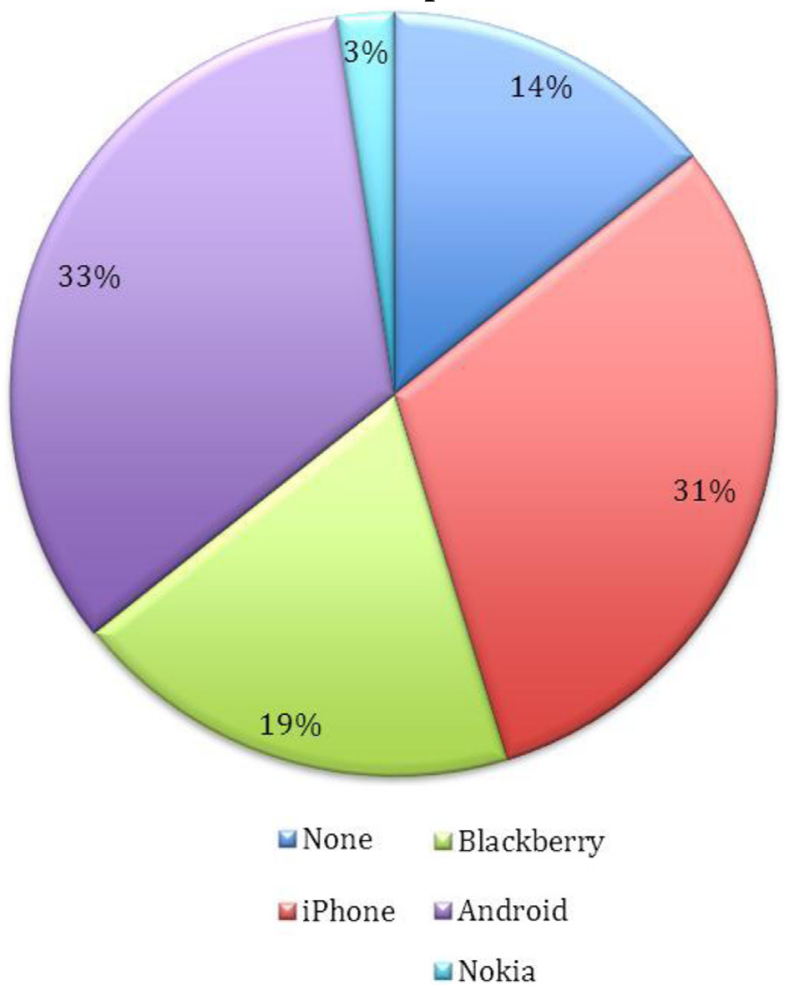

Chart 5. Percentage and breakdown of smartphone access.

A total of $79 \%$ of respondents $(n=33)$ are active Facebook users, e.g. regularly update profiles, share photographs, participate in groups, and so on, whereas $58 \%$ of respondents are active Twitter users $(n=24)$. This could demonstrate the larger market share of Facebook amongst the student population.

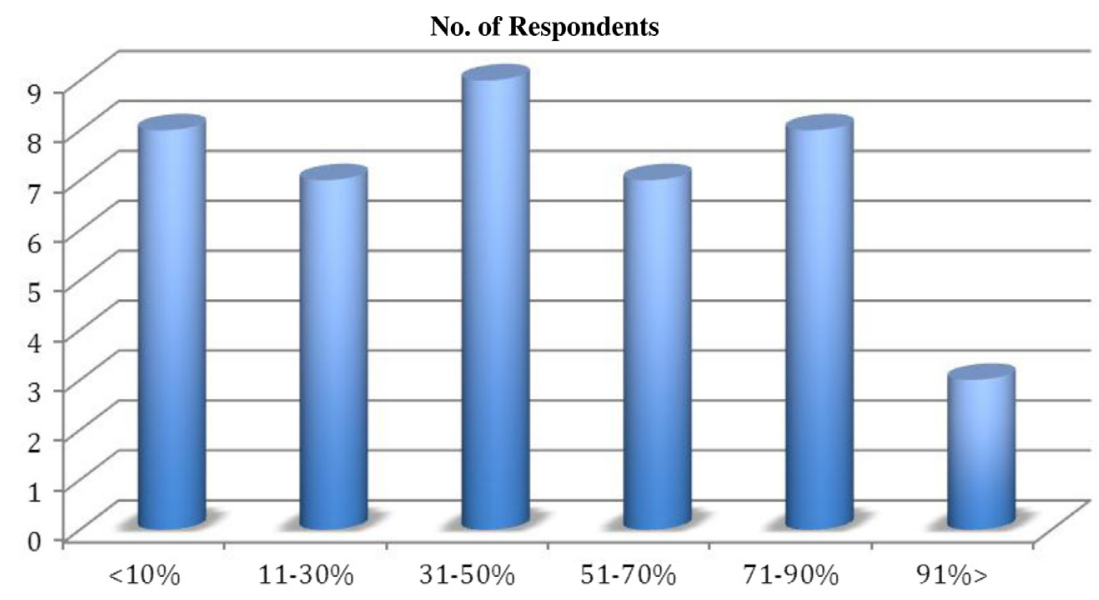

Chart 6. Percentage of overall Internet access via smartphone. 
Table 4. Overall Internet access via smartphone by age group.

\begin{tabular}{lcc}
\hline$\%$ & $18-24$ & $25-34$ \\
\hline$<10$ & 7 & 1 \\
$11-30$ & 6 & 1 \\
$31-50$ & 6 & 3 \\
$51-70$ & 7 & 0 \\
$71-90$ & 8 & 0 \\
$90>$ & 3 & 0 \\
\hline
\end{tabular}

An additional question was included in the questionnaire for the \#0002, \#0004 and \#0005 modules, asking respondents if they had used Facebook to discuss course related information with fellow students. One hundred per cent $(n=33)$ of existing Facebook users had used the platform to discuss course related information on an informal basis.

Table 5 identifies a mix in views related to the use of SNSs for educational activities.

There was a different view on whether Facebook or Twitter should be used in education. Whilst 29\% $(\mathrm{n}=12)$ of respondents believe Facebook should not be used, only $2 \%(n=1)$ believe Twitter should not be used. Suggesting students might perceive the role of these tools differently.

A total of $45 \%(n=19)$ and $67 \%(n=28)$ of respondents were positive towards the use of Facebook or Twitter in education, respectively.

Students were asked what their single preferred method of formal communication was and were given the options of Email, Twitter, Facebook or Moodle (Chart 8).

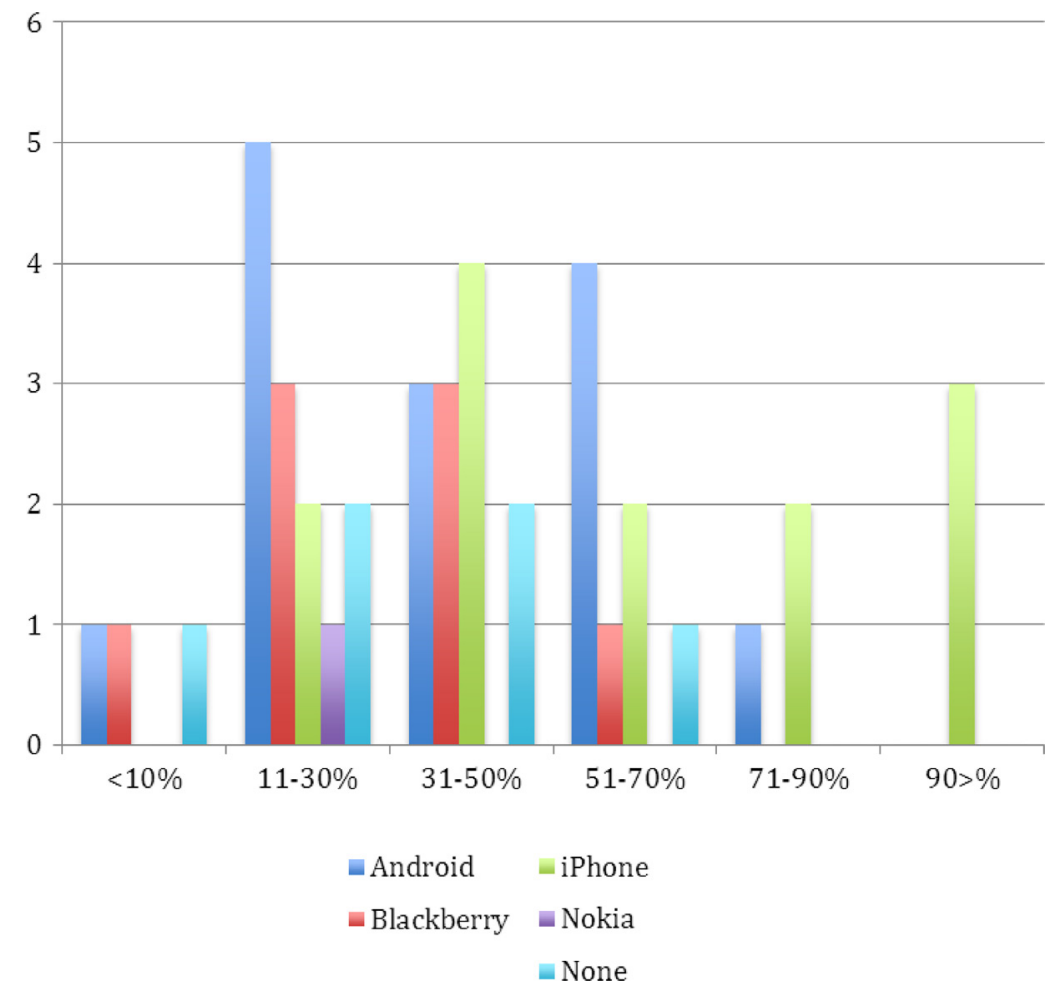

Chart 7. Number of smartphone users and their time spent in social networking (\%). 
Table 5. Should teaching staff use SNSs to communicate with students?

\begin{tabular}{lccc}
\hline Should staff use SNSs to communicate with students? & Yes & No & Indifferent \\
\hline Facebook & $19(45 \%)$ & $12(29 \%)$ & $11(26 \%)$ \\
Twitter & $28(67 \%)$ & $1(2 \%)$ & $13(31 \%)$ \\
\hline
\end{tabular}

Although many respondents are happy to use SNSs to communicate, Email still carries the most weight as the single preferred method for formal teacher-student communication $(60 \%, \mathrm{n}=25)$, followed by Moodle and Twitter (both with $14 \%$, $\mathrm{n}=6)$ and Facebook $(12 \%, \mathrm{n}=5)$.

All respondents in the 25-34 age category preferred email to other methods.

Table 6 includes responses to a free text question, asking if respondents identified benefits of using Twitter as a communication tool between teachers and students. Although the question only asked for benefits, some students included negative aspects as well. The responses have been loosely coded as below.

Fifty-eight positive comments were made relating to the use of Twitter as a communication tool, with respondents identifying the speed of communication and ease of communication as key drivers. Participating in a public forum, feelings of community, accessing links and retweets (RTs) and the informal and relaxed nature was also deemed positive.

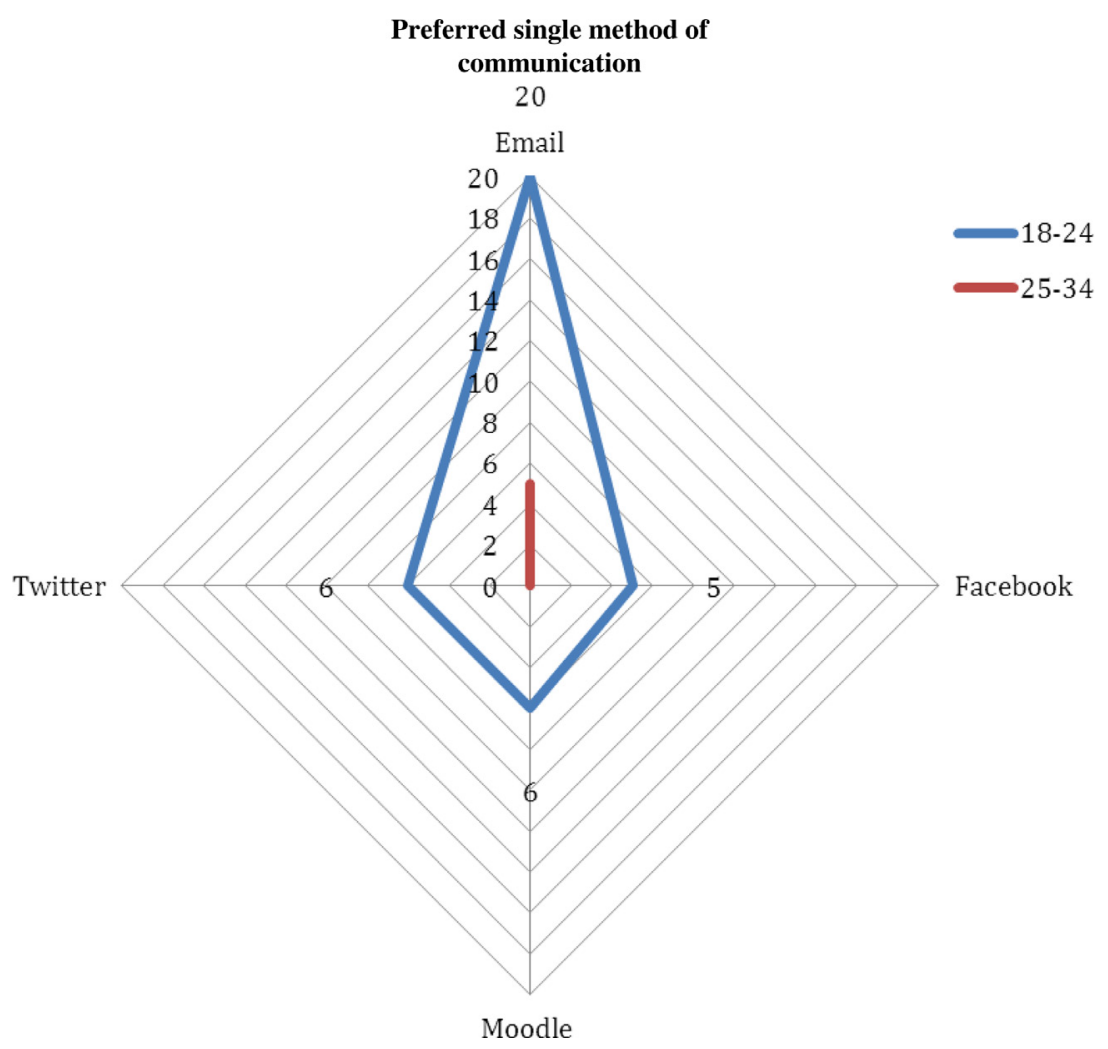

Chart 8. Preferred primary communication method amongst respondents. 
Table 6. Comments related to use of Twitter.

\begin{tabular}{lrlc}
\hline Positive response & Count & \multicolumn{1}{c}{ Negative response } & Count \\
\hline Ease & 11 & Moodle for important info & 1 \\
Speed & 22 & Twitter can be a distraction & 1 \\
Infrequent email use & 1 & No reason given & 4 \\
Mobile notifications & 2 & Facebook more appropriate & 1 \\
Public forum and feeling of community & 8 & & \\
Links and retweets & 6 & & \\
Informal/relaxed/personal & 5 & & 7 \\
No reason given & 3 & & \\
Total & 58 & & \\
\hline
\end{tabular}

Table 7 demonstrates that a smaller number of respondents actually used Twitter to communicate with tutors $(36 \%, \mathrm{n}=15)$, with $100 \%$ of this group finding this method of contact a useful exercise. Interestingly, more respondents contacted other students $(40 \%, \mathrm{n}=17)$ rather than their tutors.

Exactly $50 \%$ of respondents $(n=21)$ had accessed a link posted by the tutor, which incidentally was greater than the amount of respondents who had communicated with the tutor via the platform.

\section{Discussion}

Only $36 \%$ of respondents $(n=15)$ communicated with tutors through Twitter; however all of those that did, found the service beneficial. Whilst this is overwhelmingly positive, there are other factors to consider before encouraging all students to use such services, such as existing digital literacies, habits, etc.

Interestingly, more students accessed links posted by the tutor $(50 \%, \mathrm{n}=21)$, than the amount of active Twitter users $(36 \%, n=15)$. This would suggest the Twitter API to enable tweets to display in the VLE is a feature students have actually used and might find beneficial. It reinforces the notion that students can be inactive in the Twitter environment, but can "lurk" and still benefit from social influences on the Web - a common phenomenon within communities of practice (Reed, Sherratt, and Smith 2008; Beaudoin 2002; Jansen \& Zhang 2009). It further suggests that Twitter can play a key role to aid communication between teaching staff and students, as well as encouraging and supporting informal/casual learning, that is, learning outwith the formal structures of the university, between learners, and in online communities.

The researcher witnessed a significant increase in both the number of tweets and emails from students to the tutor as deadlines approached for coursework/exams. The number of tweets by students was not recorded as very few of them contained the

Table 7. Actual usage of Twitter (totals).

Students were asked a series of Yes/No questions related to if, and how, they have used Twitter as part of their studies.

\begin{tabular}{lcc}
\hline Question & Yes & No \\
\hline Have you contacted a tutor? & 15 & 27 \\
Was this useful? & 15 & 25 \\
Have you contacted other students & 17 & 21 \\
Have you accessed a link from tutor & 21 & \\
\hline
\end{tabular}


dedicated hashtags, however the stated increase in tweets suggest that some students clearly valued Twitter over other methods in these instances. This is reinforced by the coded comments related to "Speed" and "Ease" of communication (Table 6).

The reliance upon email as the single preferred method for formal communications by the majority of respondents $(60 \%, \mathrm{n}=35)$ suggests students still value this communication mechanism. This might contradict data and views from both Pew (Lenhart et al. 2007) and Junco, Heiberger, and Loken (2011) related to decreasing email usage, or alternatively in this case, it could merely be about security - providing a means for students to return to and archive important messages, as opposed to the potential for tweets to be missed on busy timelines.

As this is an isolated study, it is difficult to compare the use of email with the previous year's students, so we therefore cannot be sure if email reliance is decreasing or not. Furthermore, the small number of respondents in the "older" age category prevents any generalisations in relation to their reliance on email as a single preferred method of communication.

\section{Social media and the digital divide}

The data obtained in this study identifies a difference in time spent online between age groups - all of the 25-34 year old respondents spend less than 40 hours online per week. It also demonstrates that whilst not all students are active users of SNSs, there is no correlation between "active SNS use" and "Age". However, the data in Tables 4 and 5 demonstrates that only one of the "older" respondents engages with social networking to any significant degree, e.g. $>50 \%$ of their overall time online, and does not rely on their smartphone for more than $50 \%$ of their overall online activity. In both questions, respondents in the lower age bracket demonstrated greater use of social networking, as well as a greater reliance on mobile technologies.

This provides an interesting insight into the digital divide. Although there appears to be a distinction between both extremely high uses of social networking and reliance on mobile devices, with "Age", respondents in the 25-34 age bracket still engage online and in social networking, contradicting suggestions by Prensky, and potentially reinforcing White and Le Cornu's perspective that the Native/Immigrant classifications do not lend themselves to the Social Web, and thus require rethinking. The data therefore is in closer alignment to the idea of Digital Visitors and Residents, whereby residents see the social web as a physical place, as opposed to visitors who use the tools they need to perform a certain task (White \& Le Cornu 2011). This is reinforced through the development of a community of learners, consisting of so-called Natives and Immigrants.

In recognising White and Le Cornu's notion of the Digital Visitor, we also recognise the need to support the digital literacies of students in order to harness the potential of Web 2.0 tools. This would support the view of Dabbagh and Kitsantas (2011) that students should receive suitable training in social media tools. This is particularly relevant, given that $100 \%$ of active Twitter users positively evaluated the service in relation to learning and teaching, and in particular in relation to supporting and enhancing communication. Whilst there may be differing circumstances, literacies, habits, and so on amongst the diverse student population, we can presume many other students would also have seen benefits had they been active also. Therefore, it is essential to enable all students, not just Digital Visitors, to become 
fluent and use the tools to enhance learning and the student experience as they see fit. Again, suitable awareness raising and support events may be required to achieve this.

\section{Social media and PLEs}

This research supports the beliefs of a number of commentators (Dabbagh \& Kitsantas 2011; Hall 2009) that students are already choosing social media tools in the formation of their own PLEs; Chart 9 identifies 79\% $(n=33)$ and 57\% $(n=24)$ of respondents already actively using Facebook and Twitter respectively, before beginning these modules. This information suggests PLEs are owned and formed through personal choice, views and considerations, and that learners are already using these tools to support their learning in casual (or informal) settings. This is further reinforced by data identifying that $98 \%$ of active Facebook users had already used that platform to discuss university work.

This study emphasised the voluntary participation with Twitter for a number of reasons [in contrast to the enforced approach adopted in previous studies of Junco, Heiberger, and Loken (2011) and Kassens-Noor (2012)], but notably for one of personal freedom in the formation of a meaningful PLE - if PLEs are indeed personal and assembled through personal choice, we cannot enforce specific tools or environments upon students without running the risk of disengagement. Similarly, how can such technologies be classed as informal, if they are integrated formally within curricula? Instead, learners should be shown the potential of such tools amongst a learner's repertoire or toolkit, with the hope that voluntary participation will be more likely to encourage meaningful and long-term use. Finally, the disregard of hashtags by

Active users of SNSs before this course active $\quad$ Not active

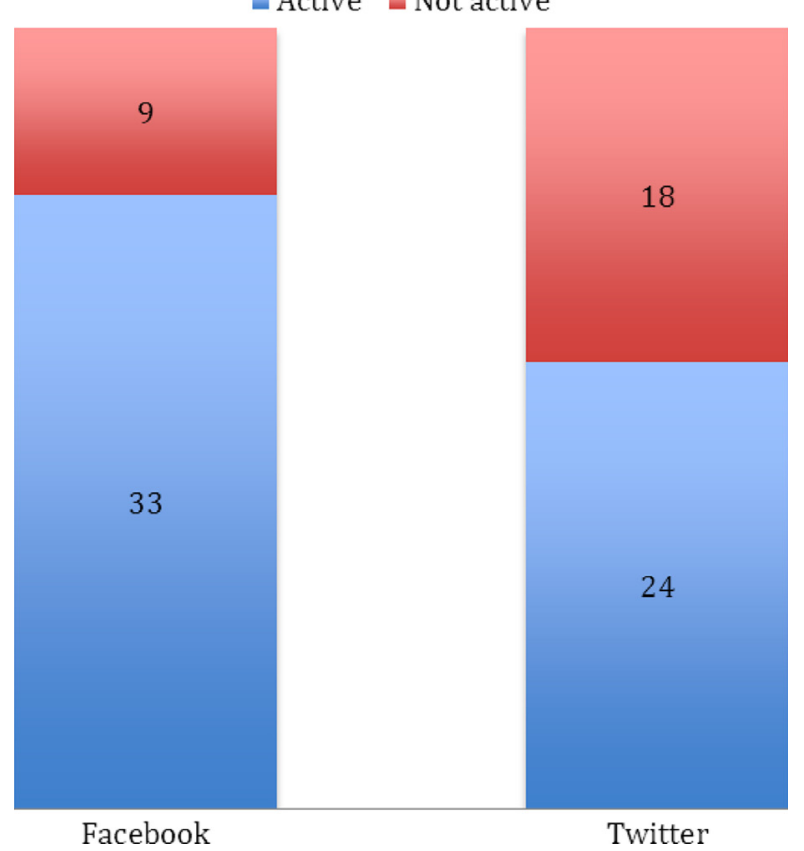

Chart 9. Active users of SNSs before beginning this course of study. 
students, whether consciously or not, could emphasise the insistence of the informal nature of the platform.

\section{Conclusion}

This exploratory study has provided a knowledge base in the underexplored area of using Twitter in education. To concur with previous authors cited, the data and discussions in this paper support the suggestion that the use of social media (and Twitter in particular) can positively impact upon various elements of teaching, learning and the student experience. In particular, this study has aligned the use of Twitter to the three Cs - Communication, Community and Casual (informal) learning - each of which has taken place between learners and teaching staff. With on-going challenges of learner isolation in higher education, the use of Twitter in this study might prove to be one potential solution to combat such problems. However, it is also important to recognise that Twitter is "not for everyone".

To further embed the positive experiences cited in earlier studies as well as those identified here, it is recommended that researchers look to archive tweets beforehand in order to sufficiently analyse social/group dynamics. Furthermore, support/training around the use of the tools is critical to get a wider uptake and to ensure students fully understand the features, e.g. hashtags.

The data gathered in this study provides some insight into the digital behaviours of students aged 25-34, however due to the low response rate obtained it is difficult to generalise this information to anything wider than this case in particular. It does reinforce White and Le Cornu's (2011) notion of Digital Residents and Visitors, and as such prompts further research into the digital behaviours of learners, with a particular focus on age. Through such further investigation, it also raises questions related to whether age, or more specifically the level of digital literacy, should be the primary focus of investigation.

To conclude this paper, three questions have arisen through interacting with literature and the data gathered:

(1) Should educational institutions take responsibility for familiarising learners with emerging technologies and embed them into learning and teaching activities? If so, how?

(2) If students are already using Twitter as a personal/social tool, are there ethical issues involved in archiving and analysing their tweets/discussions?

(3) If PLEs are indeed personal and these tools are informal, do we run the risk of disengaging students by formalizing them through structure?

This single case reinforces the notion that Twitter can be a useful tool to support learning and teaching, and warrants further investigation into the use of social media to enhance the overall student experience beyond the direct impact on assessment marks. As highlighted earlier, further research might consider analysing more closely the amount of tweets as well as group dynamics. However, the use of particular hashtags alone does not tell the full story, and therefore closer research into the impact of using such tools as a means to enhance communication, collaboration and casual (informal) learning is needed. 


\section{Bibliography}

Beaudoin, M. F. (2002) 'Learning or lurking? Tracking the "invisible" online student', Higher Education, vol. 5, pp. 147-155.

BERA (2011) Ethical Guidelines for Educational Research, London.

Boyd, D. M. \& Ellison, N. B. (2008) 'Social network sites: definition, history, and scholarship', Journal of Computer-Mediated Communication, vol. 13, no. 1, pp. 210-230.

Chickering, A. W. \& Gamson, Z. F. (1999) 'Development and adaptations of the seven principles for good practice in undergraduate education', New Directions for Teaching and Learning, vol. 80, pp. $75-81$.

Dabbagh, N. \& Kitsantas, A. (2011) 'Personal learning environments, social media, and selfregulated learning: a natural formula for connecting formal and informal learning', The Internet and Higher Education, vol. 15, no. 1, pp. 3-8.

Hall, R. (2009) 'Towards a fusion of formal and informal learning environments: the impact of the read/write web', Learning, vol. 7, no. 1, pp. 29-40.

Jansen, B. J. \& Zhang, M. (2009) 'Twitter power: tweets as electronic word of mouth', Journal of the American Society for Information Science, vol. 60, no. 11, pp. 2169-2188.

Junco, R., Heiberger, G. \& Loken, E. (2011) 'The effect of Twitter on college student engagement and grades', Journal of Computer Assisted Learning, vol. 27, no. 2, pp. $119-132$.

Kassens-Noor, E. (2012) 'Twitter as a teaching practice to enhance active and informal learning in higher education: the case of sustainable tweets', Active Learning in Higher Education, vol. 13, no. 1, pp. 9-21.

Lenhart, A., et al., (2007) Teens and Social Media, Available at: http://www.pewinternet.org/ Reports/2007/Teens-and-Social-Media.aspx.

Pepitone, J. (2012) Facebook IPO: What the \%\$\#! happened? CNN Money. Available at: http:// money.cnn.com/2012/05/23/technology/facebook-ipo-what-went-wrong/index.htm.

Prensky, M. (2001) 'Digital natives, digital immigrants part 1', On the Horizon, vol. 9, no. 5, pp. $1-6$.

Reed, P., Sherratt, C. \& Smith, B. (2008) 'A new age of constructivism: "mode neutral", E-Learning, vol. 5, no. 3, pp. 310.

Roblyer, M. D., et al., (2010) 'Findings on Facebook in higher education: a comparison of college faculty and student uses and perceptions of social networking sites.' The Internet and Higher Education, vol. 13, no 3, pp. 134-140. Available at: http://linkinghub.elsevier. com/retrieve/pii/S1096751610000278.

Schofield, M. (2006) 'The SOLSTICE Concept and Application - synergising research, evaluation and enhancement for intelligent deployment of technologies to support learning', in Current Developments in Technology Assisted Education, eds A. MendezVilas, A. Solano Martin \& J. Mesa Gonzalez, Formatex, Badajoz, Spain, pp. 666-671, ISBN 978-84-690-2471-X.

Selwyn, N. (2009) 'The digital native - myth and reality', Aslib Proceedings, vol. 61, no. 4, pp. 364-379.

The Office for National Statistics (2013) Statistical Bulletin Internet Access - Households and Individuals (Part 2), London, England.

Vygotsky, L. S. (1967) 'Play and its role in the mental development of the child'. Soviet Psychology, vol. 5, no 3, pp. 6-18. British translation available at: http://www.marxists.org/ archive/vygotsky/works/1933/play.htm.

White, D. \& Le Cornu, A. (2011) 'Visitors and residents: a new typology for online engagement', First Monday, vol. 16, no. 9. Available at: http://firstmonday.org/htbin/ cgiwrap/bin/ojs/index.php/fm/article/viewArticle/3171/3049.

YouGov (2012) Social Media "Growing Up" in the UK (February 2012). Available at: http:// yougov.co.uk/news/2012/02/17/social-media-growing-uk/. 


\section{Appendix 1 - Student Questionnaire}

\section{Section 1 - Student Profile}

This section aims to develop a profile of your current Internet activity.

1 . What is your gender?

Male

Female

2. What is your age bracket?
a) $18-24$
b) $25-34$
c) $35-44$
d) $45+$

3. Where do you mainly access the Internet?
a) Home
b) University
c) On the move
d) Other (Please specify)

4. What is your main Internet device?
a) Computer
b) Laptop
c) Smartphone
d) Tablet

5. How many hours per week do you use the Internet?

(Free text)

6. What percentage of your total Internet time is spent on the following activities:
a) Social networking (Facebook, Twitter, etc.)
b) Gamin
c) Online video
d) Shopping
e) News and weather
f) Banking
g) Activities related to study

(each option has multiple choices - < 10\% | 11-30\% | 31-50\% | 51-70\% | 71-90\% | 91-100\%)

7. Do you own a smartphone?
a) Yes
b) No

7a) If yes, which smartphone do you own?

iPhone

Blackberry

Android

Other (please specify)

8) What percentage of your Internet activity is on the following devices?
a) Computer
b) Laptop
c) Smartphone
d) Tablet

(each option has multiple choices - < 10\% | 11-30\% | 31-50\% | 51-70\% | 71-90\% | 91-100\%) 
Section 2 - Use of Social Networking

This section is specifically related to your use of social networking

9) Are you an active Facebook user i.e. do you regularly update your profile AND/OR share photographs AND/OR participate in groups, etc.?

a) Yes

b) No

9a) If yes, Have you discussed university work on Facebook in any way?

Yes

No

10) Are you an active Twitter user i.e. tweet AND/OR share photographs, etc.?

a) Yes

b) No

11) Do you think university teachers should use Facebook to communication with students (either by becoming "friends" or through groups/pages)?
a) Yes
b) No
c) Indifferent

12) Do you think teachers should use Twitter to communicate with students?
a) Yes
b) No
c) Indifferent

13) Which is your preferred method of teacher-student communication?
a) Facebook
b) Twitter
c) Email
d) Moodle (announcements, etc.)

14) Do you perceive any benefits of using Twitter as a communication tool with university teachers?

(Free text response)

15) Have you contacted a university tutor through Twitter (socially or related to the course of study)?

a) Yes

b) No

15a) If yes, have you found it a useful way to communicate with university teachers? Yes

No

16) Have you contacted other students through Twitter (either socially or related to the course of study)?

a) Yes

b) No

17) Have you access a link posted by a University teacher on Twitter?

a) Yes

b) No 